\title{
ВЛИЯНИЕ БЮДЖЕТНОЙ ПОЛИТИКИ НА МЕЖБЮДЖЕТНЫЕ ОТНОШЕНИЯ
}

\begin{abstract}
АНнотАция. В статье показана роль межбюджетных отношений в системе органов власти федерального центра, субъектов Федерации и местного самоуправления как действенного механизма государственного регулирования социально-экономического развития федеративного государства. Определены принципы построения межбюджетных отношений. Представлены различные определения термина «межбюджетные отношения», за которыми следуют различия в объеме понятия и степени охвата проблем и вопросов. Предложены основные направления бюджетной политики, направленные на создание эффективного механизма межбюджетного взаимодействия. Сделан вывод о том, что для усиления эффективности системы межбюджетных отношений следует продолжать практическую отработку финансовых механизмов, стимулирующих проведение на региональном уровне экономических и бюджетных реформ. Обосновано, что система финансовой помощи бюджетам других уровней должна быть направлена на выравнивание бюджетной обеспеченности регионов (муниципалитетов) и обеспечение доступа граждан, вне зависимости от места их проживания, к основным бюджетным услугам и социальным гарантиям при одновременном создании стимулов для проведения на региональном (местном) уровне рациональной и ответственной налогово-бюджетной политики и повышения эффективности бюджетных расходов.
\end{abstract}

кЛючЕВЫЕ слОВА. Межбюджетные отношения; бюджетная политика; бюджетный федерализм.

ИНФОРМАЦИЯ О СТАТЬЕ. Дата поступления 12 мая 2016 г.; дата принятия к печати 6 июня 2016 г.; дата онлайн-размещения 25 июля 2016 г.

V. I. Vladimirov

Baikal State University,

Irkutsk, Russian Federation

\section{INFLUENCE OF BUDGET POLICY ON INTER-BUDGET RELATIONS}

\begin{abstract}
The article shows the role of inter-budget relations in the system of organs of power of the Federal Center, federal enities and local-self-governments as a viable emchnism of governmental regulation of socio-economic development oft the federal state, It specifies the principles of building inter-budget relations. It presents various definitions of the term «inter-budget relations» which are followed by the differences in the volume of the term and the degree of coverage of problems and issues. It offers basic directions of the budget policy aimed at creating an effective mechnism of inter-budget cooperation. A conclusion is made that strengthening the efficiency of the inter-budget relations system requires to continue practical development of financial mechanisms that stimulate implementation of economic and budget reforms at the regional level. The artcle substantuates that the system of financial assistance to the budgets of other levels should be aimed at levelling the budget security of the regions (municipalities) and provision of the public access, regardles of the residence, to major budget services and social guaranties while creating simultanously the stimuli for conducting rational and responsible tax-budget policy and encreasing efficiency of budget expenses at the regional (local) level.
\end{abstract}

KEYWORDS. Inter-budget relations; budget policy; budget federalism.

ARTICLE INFO. Received May 12, 2016; accepted June 6, 2016; available online July 25, 2016.

(C) В. И. Владимиров, 2016

\section{Baikal Research Journal}


Вопросы бюджетного федерализма и межбюджетных отношений в настоящее время находятся в центре внимания экономистов и политиков. В основном в научной литературе бюджетный федерализм рассматривают как отношения по разграничению бюджетных прав и полномочий, налогов и расходов между федеральными, региональными и местными бюджетами, или как совокупность принципов и механизмов бюджетно-налоговых отношений между различными уровнями государственной власти и управления.

Конституция РФ законодательно закрепила три уровня государственной власти в России (федеральную, региональную, муниципальную). Следствием этого явилось и законодательное закрепление «предметов ведения» того или иного уровня власти. Совершенно очевидно, что реализация государственных полномочий осуществляется, прежде всего, через обеспечение соответствующего финансирования, в основной своей части состоящего из бюджетных средств. Аналогично государственному устройству было сформировано и бюджетное законодательство, предусмотревшее трехуровневую бюджетную систему.

Казалось, что, решив основные вопросы государственного устройства, страна оградит себя от внутригосударственных споров и проблем.

Выработка и реализация государственной региональной политики как неотъемлемая функция государственного регулирования социально-экономического развития федеративного государства предполагают в качестве действенного механизма межбюджетные отношения между органами власти федерального центра, субъектов Федерации и местного самоуправления. Как часто бывает на практике, достаточно стройно прописанные позиции оказались тяжело интегрирующимися в реальную жизнь общества, и этому способствовало несколько причин:

- часть общегосударственных вопросов оказались в совместном ведении рядом стоящих уровней власти;

- часть вопросов, находящихся в ведении того или иного уровня власти, напрямую не могут решиться этим уровнем власти (получая заработную плату из средств федерального бюджета, граждане проживают на определенной территории, и остальные блага вынуждены получать в основном от этой территории);

- ряд руководителей как регионов, так и муниципалитетов оказались не готовыми к самостоятельному управлению территориями.

Данный список можно еще долго продолжать, но даже его часть свидетельствует о глобальности проблемы, с которой столкнулось государство, отказавшись от тоталитаризма.

Сформировав три уровня власти и три уровня бюджетного устройства, государство вплотную подошло к вопросу: «А как будут строиться отношения различных уровней власти?». Как следствие существования трехуровневой системы появилось понятие межбюджетных отношений. Само слово «межбюджетные» воспринимается многими в прямом смысле, как отношения бюджетов, но на самом деле данное понятие несколько глубже и объемнее.

Межбюджетные отношения имеют в основе своего построения следующие принципы:

- распределение и закрепление расходов бюджетов по определенным уровням бюджетной системы Российской Федерации;

- разграничение (закрепления) на постоянной основе и распределение по временным нормативам регулирующих доходов по уровням бюджетной системы Российской Федерации;

- равенство бюджетных прав субъектов Российской Федерации и бюджетных прав муниципальных образований;

\section{Baikal Research Journal}


- выравнивание уровней минимальной бюджетной обеспеченности субъектов Российской Федерации, муниципальных образований;

- равенство всех бюджетов Российской Федерации во взаимоотношениях с федеральным бюджетом, а также равенство местных бюджетов во взаимоотношениях с бюджетами субъектов Российской Федерации [1, с. 85].

Таким образом, становится очевидным, что межбюджетные отношения имеют две основные составляющие - экономическую и политическую (именно две, а не какую-либо одну, как полагают многие). Экономическая составляющая представляет собой решения вопросов «Как и куда собирать деньги?» и «Как и куда эти деньги тратить?». Политическая составляющая связана с вопросом «функциональности» или «самостоятельности» того или иного уровня власти.

Как результат построения трехуровневого государственного устройства и трехуровневой бюджетной системы возникают три уровня межбюджетных отношений: федеральный центр - регион; регион - муниципальное образование; федеральный центр - муниципальное образование. И если последний из них является, как бы, «номинальной проблемой», существующей, но оказывающей незначительное влияние на характер взаимоотношения различных уровней власти и социально-экономическое развитие территории, то первые два выступают предметом жарких споров.

В современной России вопросы сущности и механизмов реализации межбюджетных отношений на всех уровнях власти стоят особенно актуально и остро. Вместе с тем в научной литературе существует на сегодня множество определений понятия «межбюджетные отношения». За различиями в определении следуют и расхождения в объеме понятия и степени охвата проблем и вопросов.

По мнению А. Г. Игудина, в расширенной трактовке межбюджетные отношения - это отношения между органами власти по поводу разграничения на постоянной основе видов расходов и доходов, поступающих в бюджетную систему страны, а также нормативного распределения регулирующих налогов на временной основе и перераспределения средств между бюджетами в целях территориального выравнивания до уровня государственных номинальных социальных стандартов и с учетом налогового потенциала территории [2, с. 15].

Данная трактовка межбюджетных отношений представляет интерес и, несомненно, имеет ярко выраженный углубленный характер.

Углубленный характер имеет формулировка А. С. Петрухнова, предлагающего ввести в научно-практический оборот понятие «отношения и механизм межбюджетного взаимодействия» с целью более четкого разграничения и объединения в общую группу родственных, но не однозначных понятий собственно межбюджетных отношений и отношений межбюджетного регулирования $[3$, с. 9]. Действительно, до сих пор в экономической литературе отсутствует четкое методологическое разграничение и обоснование характера их взаимосвязи. Введение категории отношений межбюджетного взаимодействия позволяет решить эту проблему. Такие отношения включают в себя две группы:

- отношения между различными органами власти по поводу разграничения на постоянной основе доходов и расходов по звеньям бюджетной системы;

- отношения по поводу отчислений от регулирующих доходов на временной основе нижестоящим бюджетам и перераспределения доходов между звеньями бюджетной системы с целью территориального выравнивания и покрытия дефицита [2, с. 16].

Отношения межбюджетного взаимодействия составляют экономическое содержание одноименного механизма. Он представляет собой организацию отношений межбюджетного взаимодействия в определенную систему форм и методов их реа-

\section{Baikal Research Journal}


лизации на основе принципов бюджетного федерализма. $К$ таким принципам относятся: единство общегосударственных, территориальных и личных интересов; сочетание централизма и децетрализма в области разграничения доходов и расходов по звеньям бюджетной системы; бюджетная самостоятельность и ответственность органов власти каждого уровня; бюджетная самодостаточность каждого звена бюджетной системы; активное участие субъектов Федерации в реализации бюджетно-налоговой политики государства.

Таким образом, механизм межбюджетного взаимодействия состоит из двух элементов: системы межбюджетных отношений и системы межбюджетного регулирования.

Более глубокая трактовка межбюджетных отношений заключается в их понимании как системно организованных денежных потоков и связей между субъектами межбюджетных отношений по формированию, распределению и использованию бюджетных фондов и грантов.

В этом случае, во-первых, в систему межбюджетных отношений вовлекаются члены общества (физические лица) - получатели бюджетных пособий); во-вторых, важное значение приобретает проблема финансовых кругооборотов (их направленность, организация, регулирование, устойчивость, воспроизводимость); в-третьих, становится первостепенной проблема потенциалов бюджетных фондов, формируемых и распределяемых посредством системы межбюджетных отношений. Органы власти при правильной трактовке сущности межбюджетных отношений выступают лишь как посредники между государством и членами общества по финансовому обеспечению предоставления социальных благ в соответствии с установленными нормами и стандартами, а также возможностями государства.

Основными функциями таких отношений являются выравнивание бюджетной обеспеченности тех территориальных образований, где она меньше минимально необходимого (обеспечивающего соблюдение конституционных и других государственных социальных гарантий на всей территории страны) уровня, и стимулирование наращивания налогового потенциала, своевременного и полного сбора платежей в бюджет на подведомственной территории, а также рационального и эффективного их расходования [4, с. 9]. Обе эти функции подлежат реализации в основном в их сочетании. Поэтому, когда выравнивающая функция становится резко преобладающей, вступая в противоречие со стимулирующей функцией, в ущерб ей, требуется внесение коррективов в действующий механизм межбюджетных отношений.

Состояние межбюджетных отношений внутри субъектов Федерации в значительной степени зависят от того, как они складываются между федеральным центром и регионами. Межбюджетные отношения должны стать серьезным фактором экономического роста, но без особой заинтересованности в таком росте и ответственности за его обеспечение со стороны региональных и местных властей на подведомственных им территориях эту задачу не решить.

Между тем, из двух основных функций межбюджетных отношений в последние годы все в большей степени преобладает выравнивающая функция. Это вызывает рост иждивенческих настроений на местах как результат все нарастающего усиления централизации и перераспределения средств в регионы через федеральный бюджет в форме безвозмездных перечислений. В субъектах Федерации разработаны свои методы образования и распределения финансовой помощи местным бюджетам.

Новое бюджетное законодательство диктует соответствующую унификацию в определении этой помощи. Такой подход, если он предусматривает жесткую детализацию (например, сколько и каких фондов межбюджетного регулирования долж-

\section{Baikal Research Journal}

электронный научный журнал Байкальского государственного университета 
но быть в составе регионального бюджета, запрет на использование фактических и прогнозных данных и др.), не бесспорен в условиях федеративного государства. Он сковывает инициативу по поиску в регионах оптимальных решений, руководствуясь общими принципами и наиболее общими целями финансового выравнивания, определяемыми федеральным центром.

В основе бюджетной политики лежит ряд принципов. Она является органической частью общей экономической политики государства. Предполагает сбалансированность экономики. Обеспечивает стимулирующую роль бюджетных средств, их активное воздействие на развитие производства. Носит плановый и социальный характер.

Таким образом, основными направлениями бюджетной политики, направленной на создание эффективного механизма межбюджетного взаимодействия, следует считать следующие:

- реструктуризацию бюджетной системы с позиций рационального закрепления за каждым ее уровнем доходных и расходных полномочий с ориентацией на собственные налоговые источники при формировании территориальных бюджетов, а не на финансовую помощь;

- сбалансирование прав и обязанностей органов государственной власти и местного самоуправления;

- законодательное закрепление на федеральном уровне бюджетных полномочий во взаимоотношениях между субъектами Российской Федерации и муниципалитетами;

- разработку единой рациональной методологии определения финансовой помощи региональным и местным бюджетам;

- установление единых регламентов деятельности органов власти всех уровней в бюджетном процессе.

В России, продолжающей свое движение по пути экономических реформ и структурной перестройки не только экономической, но и политической систем, особое внимание уделяется построению и нормальному функционированию бюджетной системы государства, этому вопросу посвящены и труды многих исследователей [5-11].

Для усиления эффективности системы межбюджетных отношений следует продолжать практическую отработку финансовых механизмов, стимулирующих проведение на региональном уровне экономических и бюджетных реформ. Работа по совершенствованию методологии бюджетного выравнивания с законодательным закреплением ее основных положений на среднесрочную перспективу продолжается. Объем финансовой помощи из федерального бюджета в последние годы имел тенденцию к росту в связи с тем, что доходы бюджетов субъектов Федерации очень неравномерны. Федеральный бюджет должен обеспечить выравнивание бюджетной обеспеченности, чтобы государственные гарантии по образованию, здравоохранению, социальной помощи во всех субъектах Федерации выполнялись в соответствии с федеральными стандартами [12, с. 44].

От решенности вопроса межбюджетных отношений во многом зависит стабильность функционирования всей государственной системы. Специфика межбюджетных отношений такова, что именно они в значительной степени определяют пути развития территорий и содержат ответы на насущные вопросы как представителей власти, так и простых граждан. Таким образом, вопрос понимания общественностью значимости этого вопроса, а также возможность влиять и участвовать в его решении становится актуальной задачей.

При рассмотрении существующих и прогнозируемых проблем межбюджетных отношений практически невозможно получить объективную оценку, не просматри-

\section{Baikal Research Journal}


вая два уровня этих отношений (центр - регион и регион - муниципалитет) совместно. Субъекты РФ, находясь посередине иерархии власти, вынуждены решать сразу две проблемы, связанные с межбюджетными отношениями (регион - центр и регион - муниципалитет). Естественно, первая задача для региона более привлекательна и решается, как правило, с большим энтузиазмом и энергией.

Проблемы межбюджетных отношений на уровне "регион - муниципалитет» являются уменьшенной копией федеральных межбюджетных отношений. Проблемы внутрирегиональных межбюджетных отношений не менее остры, чем изложенные ранее, но с учетом региональной специфики, более ограниченной территории и ограниченной вариантности имеют более выраженную политическую окраску, нежели экономическую. Основные источники возникающих конфликтов практически одинаковы:

- нежелание муниципалитетов мириться с ограничением экономической и политической самостоятельности и превращаться в вотчину губернатора;

- накопление проблем в социально-экономической сфере муниципалитетов в настоящее время происходит быстрее, чем их решение, что приводит к недовольству общественности и может играть решающую роль при «демократическом» выборе того или иного кандидата в руководители муниципального образования.

При этом, чтобы бюджет был надежным инструментом реализации экономической и социальной политики, необходимо обеспечить его прозрачность для всех членов общества.

Проблема взаимоотношений бюджетов различных уровней в условиях российской экономики имеет два аспекта. С одной стороны, речь должна идти о взаимоотношениях между федеральным бюджетом и бюджетами субъектов Федерации; с другой, о финансовых отношениях между органами государственного управления и структурами местного самоуправления.

Современный механизм распределения средств между бюджетами разных уровней в России посредствами оказания финансовой помощи должен быть ориентирован на решение задачи горизонтальной сбалансированности бюджетов. Иначе говоря, этот механизм необходимо настроить на корректирование диспропорций в стоимости и потреблении государственных услуг в различных регионах страны. Ибо центральное правительство, обладая гораздо более широкими возможностями макроэкономического регулирования и получения налоговых поступлений по сравнению с нижестоящими уровнями власти, может и обязано посредством оказания финансовой помощи за счет средств, аккумулированных в федеральном бюджете, устранять этот дисбаланс [1, с. 85].

Не следует забывать, что, несмотря на провозглашенные установки на ориентацию современной финансовой политики российского государства на принципы бюджетного федерализма, ныне действующий механизм оказания финансовой помощи реально сформировался на базе жесткого централизма единой бюджетной системы бывшего СССР, преследовавшего по существу одну цель - обеспечить баланс между доходами и расходами по каждому бюджету, т. е. ориентированного только на вертикальную сбалансированность бюджетов, даже если это балансирование культивировало иждивенчество, подавляло инициативу нижестоящих органов власти к изысканию дополнительных финансовых ресурсов. Не случайно методология формирования бюджетов была ориентирована на расходы, а не на доходы. В итоге структурный дисбаланс бюджетной обеспеченности между регионами обозначился настолько рельефно и ощутимо, что попытки сгладить его при помощи трансфертов по существу не принесли реальных результатов, а ошибки и просчеты в самом механизме трансфертов во многом только усугубили критическую ситуацию.

\section{Baikal Research Journal}


Переориентация механизма финансовой помощи региональным бюджетам посредством трансфертных платежей в определенной степени характеризует стремление формализовать процесс бюджетного выравнивания. Однако в нынешних условиях механизм трансфертов - это лишь одна из форм системы бюджетного выравнивания. Было бы неверным отождествлять его со всей системой оказания финансовой помощи регионам. Тот факт, что сегодня три четверти регионов получают трансферты, - это в значительной степени результат нерационального распределения доходных источников, которое не соответствует распределению властных бюджетных полномочий.

Необходимо отработать единые подходы к организации всех видов финансовой помощи и в максимальной степени реализовать потенциал их целенаправленного воздействия на экономику региона.

Это позволит изменить методологию бюджетного выравнивания, понимаемого как совокупность выделяемых регионам с федерального уровня средств с целью достижения определенных стандартов в предоставлении и потреблении государственных услуг на всей территории страны. Соответственно, совершенствование механизмов бюджетного выравнивания посредством оказания финансовой помощи регионам необходимо проводить в целях повышения заинтересованности органов государственной власти на местах в расширении собственной доходной базы, развитии инвестиционной активности, проведении структурных преобразований в экономике регионов.

Таким образом, система финансовой помощи бюджетам других уровней должна быть направлена на выравнивание бюджетной обеспеченности регионов (муниципалитетов) и доступ граждан, вне зависимости от места их проживания, к основным бюджетным услугам и социальным гарантиям при одновременном создании стимулов для проведения на региональном (местном) уровне рациональной и ответственной налогово-бюджетной политики и повышении эффективности бюджетных расходов. Исходя их этого она должна соответствовать следующим основным требованиям:

1. Разделение финансовой помощи в зависимости от поставленных целей и механизмов распределения на текущую и инвестиционную, а также «выравнивающую» и «стимулирующую» .

2. Выделение в составе текущей помощи дотаций, субвенций и субсидий как основных форм финансовой поддержки.

3. Распределение финансовой помощи по единой методике на основе прозрачных формул с проверяемыми расчетами объективных критериев бюджетной обеспеченности регионов либо заранее установленных условий и процедур конкурсного отбора.

4. Неприменение в расчетах бюджетной обеспеченности отчетных данных о фактически произведенных бюджетных расходах и фактически поступивших налоговых доходов.

5. Установление методик и процедур распределения финансовой помощи федеральными законами и принимаемыми на их основе нормативно-правовыми актами Правительства Российской Федерации.

6. Жесткость бюджетных ограничений: утверждение всего объема финансовой помощи конкретным регионам (муниципалитетам) законом о соответствующем бюджете, ограничения на перечисление в течение бюджетного года средств, не распределенных между регионами (муниципалитетами) законом о бюджете.

7. Максимально возможная стабильность (предсказуемость) объема и принципов распределения финансовой помощи, позволяющая субъектам Федерации (му-

\section{Baikal Research Journal}


ниципальным образованиям) самостоятельно прогнозировать для себя основной объем получаемой финансовой поддержки на среднесрочную перспективу.

8. Установление на федеральном уровне общих принципов и требований к формам и механизмам выравнивания бюджетной обеспеченности муниципальных образований.

Средства, передаваемые из одного бюджета в другой на определенные цели или без целевой привязки, являются основным источником доходов многих региональных и местных бюджетов. Россия в этом отношении не уникальна - такую же роль трансферты играют во многих странах как с развивающейся, переходной, так и развитой экономикой, причем не только в федеративных государствах, но и в странах с унитарным государственным устройством.

К бюджетным трансфертам прибегают в разных случаях:

- если бюджетная система не сбалансирована по вертикали: расходы децентрализованы более сильно, чем доходы (налоговые трансферты);

- для выравнивания возможностей регионов предоставления жителям стандартного набора бюджетных услуг (выравнивающие трансферты);

- для создания у регионов (муниципальных образований) материальной заинтересованности в проведении политики, отвечающей общегосударственным интересам («зеркальные» трансферты);

- для выравнивания обеспеченности жителей разных регионов услугами, для финансирования федеральных мандатов (целевые, в том числе постатейные, трансферты, субвенции);

- для компенсации нижестоящим бюджетам возросших расходов или потери доходов в тех случаях, когда причиной таких потерь послужило решение вышестоящего органа власти (компенсации), а также в других случаях.

В официальной российской терминологии понятие «трансферты» далеко не всегда используется в смысле «передачи средств из одного бюджета в другой». Там, где речь идет о межбюджетных трансфертах, в Бюджетном кодексе РФ используется термин «ассигнование другим уровням власти». Межбюджетные отношения являются основным финансовым инструментом реализации государственной региональной политики и укрепления единой вертикали власти. Они составляют механизм финансового обеспечения принятых решений и являются неотъемлемой частью системы государственного управления и взаимодействия органов власти различных уровней.

В результате законодательного закрепления разграничения полномочий между уровнями власти и изменения налогового и бюджетного законодательства межбюджетные отношения к началу 2015 г. претерпели существенные изменения. На основе принципа равенства бюджетов, единых методик распределения средств и ответственности органов власти всех уровней за реализацию своих расходных полномочий были установлены новые принципы формирования межбюджетных трансфертов, формы и методы финансовой поддержки регионов из федерального бюджета. Финансирование полномочий федеральных органов государственной власти, возложенных на органы государственной власти субъектов Российской Федерации, в условиях 2015 г. обеспечено путем предоставления субвенций из федерального бюджета, передачи в пользование и (или) управление либо в собственность субъекта материальных объектов. Это в свою очередь требует эффективного администрирования со стороны федерального центра. Вместе с тем поиск дополнительных источников финансирования для обеспечения своих полномочий - задача для каждого уровня власти, которая в настоящее время приобретает всю большую активность. При таком подходе полномочия различных уровней власти в соответствующей юрисдикции и их обязательства будут обеспечены законодательно и институцио-

\section{Baikal Research Journal}

электронный научный журнал Байкальского государственного университета 
нально. Это, в свою очередь, обеспечит конструктивное сотрудничество и прочность отношений между всеми уровнями власти.

Как уже было изложено ранее, общепризнанными формами финансовых межбюджетных отношений в системе реализации региональной политики являются предоставление субвенций, бюджетных кредитов и государственных гарантий соответствующим уровням государственной власти. Критерием эффективности каждой конкретной модели межбюджетных отношений должны быть увеличение экономического потенциала региона, его вклада в национальную экономику, качество и объем бюджетных услуг, предоставляемых населению.

До тех пор, пока органы власти субъектов РФ и местного самоуправления не будут обладать законодательно установленной налогово-бюджетной автономией, они не будут заинтересованы в эффективном управлении общественными финансами, реструктуризации бюджетной сферы и создании благоприятных условий для экономического развития соответствующих территорий. Только законодательно установленные налогово-бюджетные полномочия могут быть основой для реальной, поддерживаемой четкими правовыми механизмами ответственности органов власти субъектов и местного самоуправления за результаты своей финансовой и социально-экономической политики.

Формируемая система межбюджетных отношений должна базироваться на принципе равноправия, согласования интересов и взаимной ответственности ее участников. Воздействуя на процессы формирования бюджетных отношений путем изменения принципов, методов, способов формирования бюджетных доходов и расходов практически на всех стадиях бюджетного процесса, государство формирует и корректирует бюджетные взаимосвязи, регулирует каналы прохождения и направления бюджетных потоков, уточняет пропорции распределения централизованных ресурсов и методы реализации их целевого назначения, и таким образом, обеспечивает регулирование бюджетной системы страны. Однако единая направленность интересов в первую очередь зависит от того, достаточно ли четко обозначены носители этих интересов. Ими, с одной, стороны, должны быть налогоплательщики, бюджетополучатели и субъекты Федерации, а с другой, Федерация в целом, а не Правительство РФ, как это имеет место в настоящее время. Причем в этой ситуации особенно важным становится понимание того, что основные принципы государственной бюджетной политики формируются именно на федеральном уровне. Государственная бюджетная политика, охватывающая всю совокупность правоотношений участников бюджетного процесса (государства, налогоплательщиков, бюджетополучателей, финансовых посредников и контрольных органов), ориентированная на интересы регионов, не является простой совокупностью отдельных «политик» регионов страны.

Основу механизма бюджетного регулирования составляет организация целостной системы экономических отношений. Таким образом, бюджетное регулирование это - совокупность механизмов, координирующих финансовые взаимосвязи. Бюджетное регулирование обеспечивает существование бюджетной системы в условиях целостности и единства федеративного государства, и ориентировано на широкий спектр интересов всех участников бюджетного процесса в решении финансовых проблем, возникающих при закреплении определенного порядка бюджетного устройства и управлении бюджетным процессом страны.

Соответственно, совершенствование механизмов бюджетного выравнивания посредством оказания финансовой помощи регионам необходимо проводить в целях повышения заинтересованности органов государственной власти на местах в расширении собственной доходной базы, развитии инвестиционной активности, проведении структурных преобразований в экономике регионов.

\section{Baikal Research Journal}

электронный научный журнал Байкальского государственного университета 


\section{Список использованной литературы}

1. Государственные и муниципальные финансы : учеб. пособие / под ред. Г. Б. Поляка. М. : Юнити-Дана, 2004. - 303 с.

2. Игудин А. Г. Актуальные проблемы межбюджетных отношений / А. Г. Игудин // Финансы. - 2010. - № 9. - С. 15-19.

3. Стратегии социально-экономического развития регионов : материалы науч.-практ. конф. / под ред. И. Е. Рисина, Ю. И. Трещевского, В. Н. Эйтингтона. - Воронеж : Воронеж. гос. Ун-т, 2012. $-128 \mathrm{c}$.

4. Колесов А. С. Оценка финансового положения субъектов Федерации / А. С. Колесов // Финансы. - 2011. - № 8. - С. 8-13.

5. Иркутская область в XXI веке: проблемы и ресурсы развития / А. П. Киреенко, С. В. Чупров, Л. В. Санина [и др.]. - Иркутск : Изд-во БГУЭП, 2014. — 422 с.

6. Самаруха В. И. Развитие бюджетной системы Российской Федерации / В. И. Самаруха. - Иркутск : Изд-во БГУЭП, 2012. - 300 с.

7. Ляпунова Г. В. Бюджетная система : учеб. пособие / Г. В. Ляпунова, Т. В. Файберг. Иркутск : Изд-во БГУЭП, 2012. - 181 с.

8. Развитие Российского общества: социально-экономические и правовые исследования / О. В. Батурина [и др.] ; под ред. М. А. Винокурова, А. П. Киреенко, С. В. Чупрова. - М. : Наука, 2014. - 622 с.

9. Федотов Д. Ю. Особенности исполнения бюджетов российских регионов / Д. Ю. Федотов. - Иркутск : Изд-во БГУЭП, 2011. - 364 с.

10. Ляпунова Г. В. Бюджетный процесс и бюджетная политика : учеб. пособие / Г. В. Ляпунова, Т. В. Сорокина. - Иркутск : Изд-во БГУЭП, 2004. - 201 с.

11. Нестеров В. В. Налоговые доходы местных бюджетов и развитие межбюджетных отношений / В. В. Нестеров. - М. : Вуз и школа, 2003. - 305 с.

12. Кулькова В. Ю. Налоговое регулирование ассиметрии регионального развития на основе совершенствования межбюджетных отношений в России / В. Ю. Кулькова // Финансы и кредит. - 2013. — № 28 (196). - С. 12-22.

\section{References}

1. Polyak G. B. (ed.). Gosudarstvennye i munitsipal'nye finansy [Governmental and municipal finance]. Moscow, Yuniti-Dana, 2004. $303 \mathrm{p}$.

2. Igudin A. G. Topical problems of inter-budget relations. Finansy $=$ Finance, 2010, no. 9, pp. 15-19. (In Russian).

3. Risin I. E., Treshchevsky Yu. I., Eitington V. N. (eds). Strategii sotsial'no-ekonomicheskogo razvitiya regionov. Materialy nauchno-prakticheskoi konferentsii [Strategies of regional socio-economic development. Materials of Research Conference]. Voronezh State Univerrsity Publ., 2012. 128 p.

4. Kolesov A. S. Assessment of financial state of Federation's entities. Finansy $=$ Finance, 2011, no. 8, pp. 8-13. (In Russian).

5. Kireenko A. P., Chuprov S. V., Sanina L. V. et al. Irkutskaya oblast' v XXI veke: problemy $i$ resursy razvitiya [Irkutsk Oblast in the 21st century: problems and development resources]. Irkutsk, Baikal State University of Economics and Law Publ., 2014. 422 p.

6. Samarukha V. I. Razvitie byudzhetnoi sistemy Rossiiskoi Federatsii [Development of the Russian Federation's budget system]. Irkutsk, Baikal State University of Economics and Law Publ., 2012. 300 p.

7. Lyapunova G. V., Faiberg T. V. Byudzhetnaya sistema [The budget system]. Irkutsk, Baikal State University of Economics and Law Publ., 2012. $181 \mathrm{p}$.

8. Baturina O. V. et al.; Vinokurov M. A., Kireenko A. P., Chuprov S. V. (eds). Razvitie rossiiskogo obshchestva: sotsial'no-ekonomicheskie i pravovye issledovaniya [The Russian society development: socio-economic and legal research]. Moscow, Nauka Publ., 2014. 622 p.

9. Fedotov D. Yu. Osobennosti ispolneniya byudzhetov rossiiskikh regionov [Features of execution of budgets of Russian regions]. Irkutsk, Baikal State University of Economics and Law Publ., 2011. 364 p.

10. Lyapunova G. V., Sorokina T. V. Byudzhetnyi protsess i byudzhetnaya politika [Budget policy and budget process]. Irkutsk, Baikal State University of Economics and Law Publ., 2004. $201 \mathrm{p}$.

\section{Baikal Research Journal}


11. Nesterov V. V. Nalogovye dokhody mestnykh byudzhetov i razvitie mezhbyudzhetnykh otnoshenii [Tax revenue of local budgets and development of inter-budget relations]. Moscow, VUZ i shkola Publ., 2003. 305 p.

12. Kul'kova V. Yu. Tax regulation of the asymmetry of regional development on the basis of improving inter-budget relations in Russia. Finansy $i$ kredit $=$ Finance and Credit, 2013, no. 28 (196), pp. 12-22. (In Russian).

\section{Информация об авторе}

Владилиров Вадим Игоревич - аспирант, кафедра экономической теории и институциональной экономики, Байкальский государственный университет, 664003, г. Иркутск, ул. Ленина, 11, e-mail: ss.murmur@yahoo.com.

\section{Author}

Vadim I. Vladimirov - PhD Student, Chair of Economic Theory and Institutional Economics, Baikal State University, 11 Lenin St., 664003, Irkutsk, Russian Federation; e-mail: ss.murmur@yahoo.com.

\section{Библиографическое описание статьи}

Владимиров В. И. Влияние бюджетной политики на межбюджетные отношения / В. И. Владимиров // Baikal Research Journal. - 2016. — T. 7, № 4. — DOI : 10.17150/24116262.2016.7(4).9.

\section{Reference to article}

Vladimirov V. I. Influence of budget policy on inter-budget relations. Baikal Research Journal, 2016, vol. 7, no. 4. DOI : 10.17150/2411-6262.2016.7(4).9. (In Russian).

\section{Baikal Research Journal}

